\title{
Hyperglycemia/hyperinsulinemia after feeding a meal of grain to young horses with osteochondritis dissecans (OCD) lesions
}

\author{
S. L. Ralston
}

\begin{abstract}
Summary
To test the hypothesis that hyperinsulinemia/hyperglycemia may be correlated with OCD, plasma glucose and insulin responses to feeding high grain rations were evaluated in 15 young Standardbred horses. Four horses had osteochondritis dissecans (OCD), the other horses were nor$\mathrm{mal}(\mathrm{NL})$. Horses with $\mathrm{OCD}$ had higher $(\mathrm{p}<.01)$ postprandial glucose and insulin responses to feeding than did NL horses. Age differences in responses were also observed. Postprandial hyperglycemia and/or hyperinsulinemia may be correlated with the development of OCD lesions in young Standardbred horses.
\end{abstract}

Keywords: $\quad$ osteochondritis dissecans, glucose, insulin, age

\begin{abstract}
Hyperglycämie/Hyperinsulinämie nach Fütterung einer Getreideration bei jungen Pferden mit Osteochondritis dissecans (OCD)
Um die Hypothese zu prüfen, daß Hyperinsulinämie/Hyperglycämie mit OCD korreliert sein kann, wurde die Reaktion von Plasmaglucose und Plasmainsulin auf die Fütterung einer getreidereichen Ration bei 15 jungen Standardbred-Pferden bestimmt. Vier Pferde hatten Osteochondritis dissecans $(O C D)$, die anderen Pferde waren normal (NL). Pferde mit OCD hatten höhere ( $p<.01)$ postprandiale Glucose- und Insulinreaktionen nach der Fütterung als NL-Pferde. Ebenso wurden Altersunterschiede bei der Reaktion beobachtet. Postprandiale Hyperglycämie und/oder Hyperinsulinämie kann mit der Entwicklung von osteochondritischen Veränderungen bei jungen Standardbred-Pferden korreliert sein.
\end{abstract}

Schlüsselwörter: Osteochondritis dissecans, Glucose, Insulin, Alter

\section{Introduction}

Osteochondritis dissecans (OCD) is a major problem in the equine industry (Grondahl 1991; Jeffcott 1991). Osteochondrotic lesions may cause lameness and reduce the perceived potential for optimal performance (Gaustad et al. 1995; Laws et al. 1993; Mcllwraith 1993, MCllwraith et al. 1991). In addition, OCD has been incriminated as a contributing factor in catastrophic breakdowns in racehorses (Krook and Maylin 1988). Osteochondritis dissecans is common in Standardbred horses, primarily affecting the hock (Hoppe 1984; Mclllwraith et al. 1991). Lesions usually develop in horses between 3 to 12 months of age and new lesions rarely appear in horses over a year old (Jeffcott 1991).

High grain rations are frequently cited as a potential cause of OCD (Glade and Belling 1986; Lewis 1995), though not all young horses fed large amounts of grain develop the problem. Ingestion of grain concentrate results in significant elevations in blood glucose which stimulate insulin release (Freestone et al. 1992; Rodiek et al. 1991; Ralston and Baile 1982; Argenzio and Hintz 1972). However glucose/insulin responses to a standard grain meal may differ markedly between individuals and may be affected by diet (Ralston 1995; Ralston et al. 1993; Jacobs and Bolton 1982). Insulin is known to affect cartilage growth through its influence on growth hormone and somatomedin release (Glade 1986). It has been hypothesized that postprandial hyperglycemia and hyperinsulinemia induced by high grain intake cause chan- ges in thyroxine and growth hormone release which in turn cause OCD (Glade 1986; Glade and Belling 1986).

Genetic predisposition to OCD has been well documented in the Standardbred horse (Gaustad et al. 1995; Grondahl and Dolvik 1993, Philsson et al. 1993). However the nature of the hereditary defect which increases the risk of OCD in horses has not been determined.

We hypothesized that grain-induced hyperglycemia/hyperinsulinemia would be greater in young horses that had radiographic evidence of OCD than in animals of the same age that were radiographically normal.

\section{Materials and methods}

Data from three two-year-old geldings, four yearling (10-14 months old) geldings and eight weanling (3-10 months old) colts were used. All horses were registered Standardbreds. Four horses (one two-year-old, two yearlings and one weanling) had radiographic evidence of $O C D$ at the time of testing $(\mathrm{OCD})$, the other eleven horses (NL) had no radiographic abnormalities. The horses were fed $50 \%$ textured sweet grain mix (Omolene 300, Purina Mills, St. Louis, MO, USA), 50\% alfalfa/grass mix hay in amounts that met or exceeded NRC (1989) nutrient recommendations for rapid growth. Rations were divided into two equal feedings. Glucose and insulin responses to feeding were measured in 14 horses four times at four week intervals. One NL weanling was only tested twice though on the same protocol as the others. Blood for glucose 
and insulin analyses was drawn from preplaced indwelling venous catheters before feeding grain ( 1.7 to $2.5 \mathrm{~kg}$, depending on age and body weight) and hay ( 2 to $3 \mathrm{~kg}$ ) at $0800 \mathrm{~h}$, then hourly for $6 \mathrm{~h}$. The blood was drawn into heparinized tubes (Vacutainer, Becton Dickinson, Inc., Rutherford, NJ), centrifuged immediately and plasma drawn off and stored at $\angle 0{ }^{\circ} \mathrm{C}$ pending analysis. Plasma glucose concentrations were determined by automated dry chemistry analysis (VetTest 8008 autoanalyzer, IDEXX Inc, Westbrook, ME). Insulin concentrations were determined by radioimmunoassay (Kit TKIN1, Diagnostic Products Corp, Los Angeles, CA) previously validated for equine insulin analysis (Freestone et al. 1991).

Rates of change in glucose and insulin and glucose/insulin ratios were calculated from the data. Glucose and insulin data were subjected to stepwise regression analysis (Analytical Software,1994) factoring the effects of trial, presence or absence of OCD, age and, where appropriate, time after feeding. For parameters that were identified by regression as contributing significantly $(p<.05)$ to the variability observed, means were compared between groups by two tailed $T$ tests. Changes over time were determined by analysis of variance appropriate for repeated measures and Tukeys Test (Analytical Software 1994).

\section{Results and discussion}

Young horses that had radiographic evidence of OCD had greater $(p<.02)$ postprandial changes in glucose and insulin when fed high grain rations than did NL horses $(n=11)$ (Tab. 1 and 2). Mean postprandial plasma glucose and insulin were higher $(p<.02)$ in OCD horses (glucose: $8.59 \pm .26$ $\mathrm{mmol} / \mathrm{L}$; insulin: $43.7 \pm 3.1 \mathrm{lU} / \mathrm{dl}$ ) than in NL horses (glucose: $7.89 \pm .08 \mathrm{mmol} / \mathrm{L}$; insulin: $27.8 \pm 1.0 \mathrm{JU} / \mathrm{dl})$. Mean rate of glucose increase was higher $(p<.05)$ in OCD horses than NL

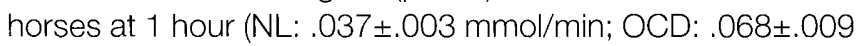
$\mathrm{mmol} / \mathrm{min}, \mathrm{p}<.01$ ) and 2 hours (NL: $-.005 \pm .002 \mathrm{mmol} / \mathrm{min}$; OCD: $.018 \pm .007 \mathrm{mmol} / \mathrm{min}, \mathrm{p}<.01$ ) after feeding. Concomitant insulin rates of increase also differed between groups

Tab. 1: Plasma glucose ( $\mathrm{mmol} / \mathrm{L}$ ) in normal versus OCD horses after feeding meals of sweet grain mix plus hay.

Plasmaglucose $(\mathrm{mmol} / \mathrm{L}$ ) bei normalen und OCD Pferden nach Fütterung einer Getreidemischung mit Heu

\begin{tabular}{|c|c|c|c|c|c|c|c|c|}
\hline & & Tim & ne after & feeding & (hours) & & & \\
\hline & 0 & $\mid 1$ & 2 & 3 & 4 & 5 & 6 & $\mathrm{SEM}^{3}$ \\
\hline$N^{\prime}{ }^{1}$ & $\begin{array}{l}6.89^{\mathrm{a}} \\
(.13)\end{array}$ & $\begin{array}{l}9.12^{\mathrm{e}} \\
(.20)\end{array}$ & \begin{tabular}{|l}
$8.85^{\text {d.e }}$ \\
$(.26)$
\end{tabular} & $\mid \begin{array}{l}8.29^{c, d} \\
(.18)\end{array}$ & $\begin{array}{l}7.78^{\mathrm{b} . c} \\
(.12)\end{array}$ & $\mid \begin{array}{l}7.29 a . b \\
(.11)\end{array}$ & $\begin{array}{l}7.04^{\mathrm{a}} \\
(.11)\end{array}$ & . 17 \\
\hline $\mathrm{OCD}^{2}$ & $\begin{array}{l}6.22^{\mathrm{a}^{*}} \\
(.17)\end{array}$ & $\mid \begin{array}{l}10.33^{c . d \times x} \\
(.52)\end{array}$ & $\mid \begin{array}{l}11.44^{d \mathrm{~d}} \\
(.06)\end{array}$ & $\mid \begin{array}{l}10.18^{\mathrm{c}, \mathrm{d}} \\
(.69)\end{array}$ & $\begin{array}{l}8.59^{b} . \\
(.50)\end{array}$ & $\mid \begin{array}{l}7.01^{a . b} \\
(.36)\end{array}$ & $\begin{array}{l}6.36^{a^{*}} \\
(.27)\end{array}$ & .49 \\
\hline
\end{tabular}

1 Values are means $( \pm \mathrm{SE})$ for 4 replicates for 10 horses and two replicates for one horse.

2 Values are means $( \pm S E)$ for 4 replicates for four horses.

3 SEM $=$ Standard error of mean.

a.b,c,d,e = Means with different superscripts differ within group $(p<.05)$.

* OCD differs from NL within time period $(p<.05)$.

${ }^{\star}$ OCD differs from NL within time period $(P<.01)$.
Tab. 2: Plasma insulin (IU/dl) in normal versus OCD horses after feeding meals of sweet grain mix plus hay.

Plasmainsulin $(\mathrm{IU} / \mathrm{dl})$ bei normalen und OCD Pferden nach Fütterung einer Getreidemischung mit Heu

\begin{tabular}{|c|c|c|c|c|c|c|c|c|}
\hline & & & Time a & ffter feed & ling (ho & urs) & & \\
\hline & 10 & 1 & 2 & 3 & $4^{4}$ & $5^{5}$ & 6 & $\mathrm{SEM}^{3}$ \\
\hline $\mathrm{NL}^{1}$ & $\begin{array}{l}10.2^{a} \\
(.8)\end{array}$ & $\begin{array}{l}35.8^{c} \\
(2.3)\end{array}$ & $\begin{array}{l}37.4^{c} \\
(2.7)\end{array}$ & $\begin{array}{l}36.9^{c} \\
(3.1)\end{array}$ & $\begin{array}{l}34.2^{\mathrm{cod}} \\
(3.1)\end{array}$ & $\mid \begin{array}{l}25.4^{b . c} \\
(1.9)\end{array}$ & $\begin{array}{l}18.9^{a, b} \\
(1.4)\end{array}$ & 2.3 \\
\hline$O C D^{2}$ & $\begin{array}{c}8.8^{\mathrm{a}} \\
(1.7)^{2}\end{array}$ & $\begin{array}{l}48.1^{b, c * \star} \\
(3.1)\end{array}$ & $\begin{array}{l}65.5^{\mathrm{c}^{* *}} \\
(6.7)\end{array}$ & $\begin{array}{l}66.1^{\star \star *} \\
(9.0)\end{array}$ & $\begin{array}{l}61.7^{b, c} \\
(10.0\end{array}$ & $\left\{\begin{array}{l}35.1^{a . b} \\
(5.4)\end{array}\right.$ & $\begin{array}{l}20.5^{\mathrm{a}} \\
(3.6)\end{array}$ & 6.3 \\
\hline
\end{tabular}

1 Values are means $( \pm$ SE) for 4 replicates for 10 horses and two replicates for one horse.

2 Values are means $( \pm S E)$ for 4 replicates for four horses.

${ }^{3} \mathrm{SEM}=$ standard error of mean.

a.b.c.d $=$ Means with different superscripts differ $(p<.05)$ within group.

* OCD differs from NL within time period $(p<.05)$ by Two way $T$ test.

${ }^{\star *}$ OCD differs from NL within time period $(P<.01)$ by Two way $T$ test.

Tab. 3: Plasma glucose $(\mathrm{mmol} / \mathrm{L})$ in NL colts 3 to 14 months old colts and geldings versus NL two-year-oldgeldings after feeding meals of sweet grain mix plus hay.

Plasmaglucose $(\mathrm{mmol} / \mathrm{L})$ bei 3 bis 14 Monate alten NLHengsten und -Wallachen sowie zweijährigen Wallachen nach Fütterung einer Getreidemischung mit Heu

\begin{tabular}{|c|c|c|c|c|c|c|c|c|}
\hline & & & Time & after fe & zeding & nours) & & \\
\hline & 0 & $\mid 1$ & 2 & 3 & 4 & 5 & 6 & SEM $^{3}$ \\
\hline $\begin{array}{l}3-14 \\
\text { month } \\
\text { old }\end{array}$ & $\begin{array}{l}7.17^{\mathrm{a}} \\
(.11)\end{array}$ & $\begin{array}{l}9.50^{d} \\
(.19)\end{array}$ & $\begin{array}{l}9.36^{d} \\
(.25)\end{array}$ & $\begin{array}{l}8.56^{\circ} \\
(.19)\end{array}$ & $\begin{array}{l}8.00^{b . c} \\
(.12)\end{array}$ & $\begin{array}{l}7.49^{a b} \\
(.11)\end{array}$ & $\begin{array}{l}7.27^{a} \\
(.11)\end{array}$ & .17 \\
\hline $\begin{array}{l}\text { Two- } \\
\text { year- } \\
\text { olds }\end{array}$ & $\begin{array}{l}5.72^{a^{*}} \\
(.32)\end{array}$ & $\begin{array}{l}7.53^{\mathrm{d} \times x} \\
(.30)\end{array}$ & \begin{tabular}{|l}
$6.71^{a b c}$, \\
$(.23)$
\end{tabular} & $\begin{array}{l}7.14 \mathrm{C}, \mathrm{d}^{*} \\
(.21)\end{array}$ & $\begin{array}{l}6.86^{b, c, d^{*}} \\
(.15)\end{array}$ & $\begin{array}{l}6.45^{a, b}, c^{* x} \\
(.15)\end{array}$ & $6.06^{a .5 * *}$ & $\begin{array}{l}.23 \\
(.16)\end{array}$ \\
\hline
\end{tabular}

1 Values are means $( \pm$ SE) for 4 replicates for 8 horses and two replicates for one horse.

2 Values are means $( \pm$ SE) for 4 replicates for 4 horses.

${ }^{3} \mathrm{SEM}=$ standard error of mean

$a, b, c, d=$ Means with different superscripts differ $(p<.05)$ within group. ${ }^{\star} \mathrm{OCD}$ differs from NL within time period $(\mathrm{p}<.05)$ by Two way $\mathrm{T}$ test.

** OCD differs from NL within time period $(P<.01)$ by Two way $T$ test.

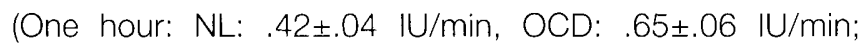
p<.001; Two hours: NL: .03 $\pm .02 \mathrm{IU} / \mathrm{min}$, OCD: $.29 \pm .07$ U/min, $\mathrm{p}<.01)$. Glucose/insulin ratios however did not differ

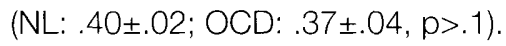

Weanling colts and yearling geldings without radiographic evidence of OCD $(n=9)$ had greater $(<.001)$ postprandial changes in glucose than did NL horses $>16$ months of age $(n=2)$ (Tab. 3). However insulin responses did not differ between the age groups ( $p>$.50) (Tab. 4). Glucose/insulin ratio was lower in the two year olds than in the younger colts ( 2 year old: $.33 \pm .03,3$ to 14 months: $.42 \pm .02$, $p<.01$ ), suggesting relative insulin resistance in the younger animals. Plasma glucose concentrations following a glucose or meal challenge may be affected by previous ration, excitement, 
Tab. 4: Plasma insulin (IU/dl) in NL colts 3 to 14 months old colts and geldings versus NL two-year-old geldings after feeding meals of sweet grain mix plus hay.

Plasmainsulin (IU/dl) bei 3 bis 14 Monate alten NL-Hengsten und -Wallachen sowie zweijährigen Wallachen nach Fütterung einer Getreidemischung mit Heu

\begin{tabular}{|c|c|c|c|c|c|c|c|c|}
\hline & \multicolumn{8}{|c|}{ Time after feeding (hours) } \\
\hline & 0 & 1 & 2 & 3 & 4 & 5 & 6 & SEM $^{3}$ \\
\hline $\begin{array}{l}\text { 3-14 } \\
\text { month } \\
\text { old }\end{array}$ & $\begin{array}{l}9.9^{\mathrm{a}} \\
(.7)\end{array}$ & $\begin{array}{l}33.3^{c . d} \\
(2.2)\end{array}$ & $\begin{array}{l}36.9^{d} \\
(3.1)\end{array}$ & $\begin{array}{l}35.7^{c, d} \\
(3.6)\end{array}$ & $\begin{array}{l}34.3^{c, d} \\
(3.6)\end{array}$ & $\begin{array}{l}25.1^{b . c} \\
(2.3)\end{array}$ & $\begin{array}{l}19.4 \\
(1.7)\end{array}$ & 2.6 \\
\hline $\begin{array}{l}\text { Two- } \\
\text { year- } \\
\text { olds² }\end{array}$ & $\begin{array}{l}11.5^{a} \\
(3.1)\end{array}$ & $\begin{array}{l}46.4 \\
(7.0)\end{array}$ & $\begin{array}{l}39.6^{c} \\
(6.3)\end{array}$ & $\begin{array}{l}41.9 \mathrm{gb} c \\
(6.2)\end{array}$ & $\begin{array}{l}34.0^{a, b c} \\
(5.3)\end{array}$ & $\begin{array}{l}26.5^{a . b} \\
(2.1)\end{array}$ & $\begin{array}{l}16.6^{a b} \\
(1.3)\end{array}$ & 4.9 \\
\hline
\end{tabular}

1 Values are means $( \pm$ SE) for 4 replicates for 8 horses and two replicates for one horse.

2 Values are means $( \pm$ SE) for 4 replicates for 4 horses.

${ }^{3} \mathrm{SEM}=$ standard error of mean

$a, b, c, d=$ Means with different superscripts differ $(p<.05)$ within group.

* OCD differs from NL within time period $(p<.05)$ by Two way $T$ test.

** OCD differs from NL within time period $(P<.01)$ by Two way $T$ test.

rate of gastric emptying, glucose absorption rates and relative insulin sensitivity (Jacobs and Bolton 1982, Argenzio and Hintz 1972). In this study the differences reported were not due to differences in rations fed. Though not all of the colts and geldings were tested at the same time, all were fed the same hay:grain ratio and baseline grain in all tests. Adaptation to the rations were the same for all tests. The same facilities, management and protocols were used in each experiment with respect to measurement of postprandial glucose and insulin. Excitement also was not a factor in the glucose/insulin responses. The colts were accustomed to being handled, regardless of age, and samples were drawn from indwelling catheters that had been preplaced 18 to 20 hours prior to the test to preclude excitement associated with repeated veinpuncture. Whether the postprandial hyperinsulinemia and hyperglycemia were due to insulin resistance or differences in glucose digestion/absorption rates were not determined in these trials.

\section{Conclusions}

Young horses with OCD lesions may have greater postprandial hyperglycemia/hyperinsulinemia when fed high grain rations than those that do not have lesions. The existence of glucose intolerance and apparent insulin resistance in horses $<14$ months old relative to horses $>16$ months old strengthens the hypothesis that hyperglycemia and/or hyperinsulinemia may be correlated with the development of OCD in young horses.

\section{References}

Analytical Software (1994). Statistixs version 4.1 User Manual, Analytical Software, Tallahassee, FL.

Argenzio, R.A. and Hintz, H. F. (1972): Effect of diet on glucose entry and oxidation rates in ponies. J. Nutr. 102, 879-892.
Freestone, J. F., Beadle, R. and Shoemaker, K. (1992): Improved insulin sensitivity in hyperinsulinaemic ponies through physical conditioning and controlled feed intake. Equine Vet. J. 24,184-186.

Freestone, J. F., Wolfshemer, K. J. and Kaermerling, S. G. (1991): Exercise induced hormonal and metabolic changes in Thoroughbred horses: effects of conditioning and acepromazine. Equine Vet. J. 23, 219-223.

Gaustad, G., Kjaerstaard, P. and Dolvik, N. I. (1995): Lameness in three-year-old Standardbred trotters-influence of parameters determined during the first year of life. J. Equine Vet. Sci. 15, 233-239.

Glade, M. J. (1986): The control of cartilage growth in osteochondrosis: a review. J. Equine Vet. Sci. 6, 175-187.

Glade, M. J. and Belling, T. H. (1986): A dietary etiology for osteochondrotic cartilage. J. Equine Vet. Sci. 6, 151-155.

Grondahl, A. M. (1991): The incidence of osteochondrosis in the tibiotarsal joint of Norwegian Standardbred trotters. J. Equine Vet. Sci. 11, 273-274.

Grondahl, A. M. and Dolvik, N. I. (1993): Heritability estimations of osteochondrosis in the tibiotarsal joint and of bony fragments in the palmar/plantar portion of the metacarpo- and metatarsophalangeal joints of horses. J. Am. Vet. Med. Assoc. 203: 101-104.

Hoppe, F. (1984). Radiological investigations of osteochondrosis dissecans in Standardbred trotters and Swedish Warmblood horses. Equine Vet. J. 16, 425-429.

Jacobs, K. A. and Bolton, J. R. (1982): Effect of diet on the oral glucose tolerance test in the horse. J. Am. Vet. Med. Assoc. 180, 884-886.

Jeffcott, L. B. (1991): Osteochondrosis in the horse - searching for the key to pathogenesis. Equine Vet. J. 23, 331-338.

Krook, L. and Maylin, G. A. (1988): Fractures in Thoroughbred racehorses. Cornell Vet. 78, Suppl 11, 5-133.

Laws, E. G., Richardson, D. W., Ross, M. W. and Moyer, W. (1993): Racing performance of Standardbreds after conservative and surgical treatment for tarsocrural osteochondrosis. Equine Vet. J. 25:, 199-202.

Lewis, L. D. (1995): Equine Clinical Nutrition. Williams and Wilkins, Philadelphia, PA. pp50-51,429-433.

Mcllwraith, C. W., Foerner, J. J. and Davis, D. M. (1991): Osteochondritis dissecans of the tarsocrural joint: results of treatment with arthroscopic surgery. Equine Vet. J. 23, 155-162.

Mcllwraith, C. W. (1993): What is developmental orthopedic disease, osteochondrosis, osteochondritis, metabolic bone disease? Proc. 39th Am. Assoc. Equine Practitioners, pp 35-44.

National Research Council (NRC) (1989): Nutrient requirements of horses. National Academy Press, Washington, DC.

Philipsson, J., Andreasson, E., Sangren, B., Dalin, G. and Carlsten, J. (1993): Osteochondrosis in the tarsocrural joint and osteochondral fragments in the fetlock joints in Standardbred trotters. Eqine vet J., Suppl. 16: 38-41.

Ralston, S. L. (1995): Bicarbonate supplementation of young horses fed high grain rations. Proc. 14th Equine Nutrition and Physiology Symposium, Pomona, CA., pp 4-5.

Ralston, S. L. (1994): Comparison of digestion and growth in yearlings fed high versus low grain rations. J Anim Sci. 72 (Suppl. 1), 262.

Ralston, S. L. and Baile, C. A. (1982): Plasma glucose and insulin concentrations and feeding behavior in ponies. J. Anim. Sci. 54, 1132-1137.

Ralston, S. L., Puzio, C. and Cuddeford, D. (1993): Dietary carbohydrates, acid base status and urinary calcium and phosphorus excretion in horses. Proc. 13th Equine Nutrition and Physiology Symposium, Gainesville, FL, pp. 42-43.

Rodiek, A., Bonvicin, S., Stull, C. and Arana, M. (1991): Glycemic and endocrine responses to corn or alfalfa fed prior to exercise. Equine Exercise Physiol. 3, 323-330.

Funded by New Jersey Agricultural Experiment Station Equine Special Initiative and Church and Dwight, Inc.

\section{S. L. Ralston}

Department of Animal Science

Cook College, Rutgers, The State University of New Jersey

P.O. Box 231

New Brunswick, NJ 08903

USA 